\title{
Parallel and four-step synthesis of natural-product- inspired scaffolds through modular assembly and divergent cyclization
}

\author{
Hiroki Oguri ${ }^{* 1}$, Haruki Mizoguchi ${ }^{1}$, Hideaki Oikawa ${ }^{1}$, Aki Ishiyama ${ }^{2}$, \\ Masato Iwatsuki ${ }^{2}$, Kazuhiko Otoguro ${ }^{2}$ and Satoshi Ōmura ${ }^{3}$
}

\section{Address:}

${ }^{1}$ Division of Chemistry, Graduate School of Science, Hokkaido University, Sapporo, Kita-ku, Hokkaido 060-0810, Japan, ${ }^{2}$ Research Center for Tropical Diseases, Kitasato Institute for Life Sciences, Kitasato University, 5-9-1 Shirokane, Minato-ku, Tokyo 108-8641, Japan and ${ }^{3}$ Graduate School of Infection Control Sciences, Kitasato University, 5-9-1 Shirokane, Minato-ku, Tokyo 108-8641, Japan

Email:

Hiroki Oguri* - oguri@sci.hokudai.ac.jp

* Corresponding author

\section{Keywords:}

chemical diversity; divergent cyclization; indole alkaloids; modular assembly; rhodium-catalyzed cyclization-cycloaddition; skeletal and stereochemical diversity
Beilstein J. Org. Chem. 2012, 8, 930-940. doi:10.3762/bjoc.8.105

Received: 06 March 2012

Accepted: 01 June 2012

Published: 22 June 2012

This article is part of the Thematic Series "Recent developments in chemical diversity".

Guest Editor: J. A. Porco Jr.

(C) 2012 Oguri et al; licensee Beilstein-Institut.

License and terms: see end of document.

\begin{abstract}
By emulating the universal biosynthetic strategy, which employs modular assembly and divergent cyclizations, we have developed a four-step synthetic process to yield a collection of natural-product-inspired scaffolds. Modular assembly of building blocks onto a piperidine-based manifold 6, having a carboxylic acid group, was achieved through Ugi condensation, $N$-acetoacetylation and diazotransfer, leading to cyclization precursors. The rhodium-catalyzed tandem cyclization and divergent cycloaddition gave rise to tetracyclic and hexacyclic scaffolds by the appropriate choice of dipolarophiles installed at modules 3 and 4 . A different piperidinebased manifold 15 bearing an amino group was successfully applied to demonstrate the flexibility and scope of the unified four-step process for the generation of structural diversity in the fused scaffolds. Evaluation of in vitro antitrypanosomal activities of the collections and preliminary structure-activity relationship (SAR) studies were also undertaken.
\end{abstract}

\section{Introduction}

Biologically intriguing natural products often possess cyclic scaffolds bearing dense arrays of functional groups and hydrogen-bond donors or acceptors. The incorporation of multiple $\mathrm{sp}^{3}$-centers on the scaffold creates a unique threedimensional shape of the surface, which is responsible for specific molecular recognition with biomacromolecules in the cellular context [1-3]. To generate diverse collections of the elaborated cyclic scaffolds, nature has evolved biosynthetic machinery and often employs (1) modular assembly and (2) divergent cyclization [4]. As the simplest example of this struc- 
tural diversification, the biosynthesis of aromatic polyketides is outlined in Figure 1a. Employing acetyl CoA as a starter unit, modular and iterative assembly of malonate extender units produces a linear tetraketide intermediate capable of being folded in at least two ways [5]. Intramolecular Claisen condensation and subsequent enolization produce phloracetophenone (path A), while aldol condensation followed by enolization and hydrolysis of the thioester yield orsellinic acid (path B). Inspired by this simple yet universal biosynthetic strategy, which generates structural variation among natural products, we envisioned the construction of chemical libraries featuring modular assembly for the rapid connection of simple building blocks, as well as divergent cyclization of a common precursor leading to distinct skeletons with complex molecular architectures.

Since the naturally occurring indole alkaloids share indole and piperidine as common substructures (Figure 1b) [6], we conceived the assembly of the substructures and subsequent intramolecular cyclization between these substructures to form the fused skeletons (Figure 1c). As a pioneering approach to shape the foundation of the "Build-Couple-Pair" (B/C/P) strategy [7-15] for diversity-oriented synthesis [16,17], a synthetic process to access indole-alkaloid-like scaffolds utilizing a piperidine-based manifold 1, was developed in 2005 [18]. By exploiting lactam, carboxylic acid and $\beta$-ketocarbonyl func-

(a) Biosynthesis

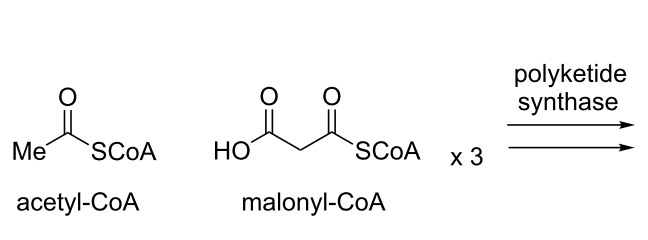

(b)

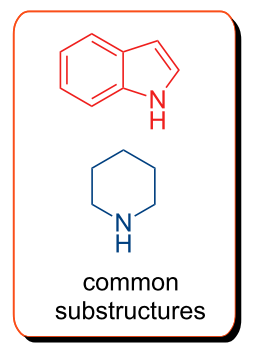

(-)-aspidospermine

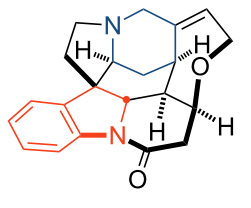

strychnine

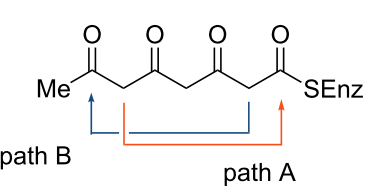

path A

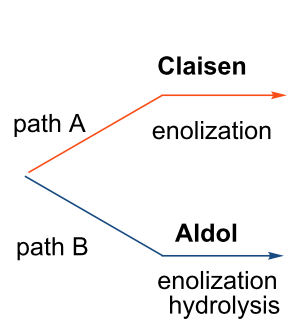<smiles>CC(=O)c1c(O)cc(O)cc1O</smiles>

phloracetophenone

$\mathrm{HO}$<smiles>Cc1cc(I)cc(O)c1C(=O)O</smiles>

orsellinic acid

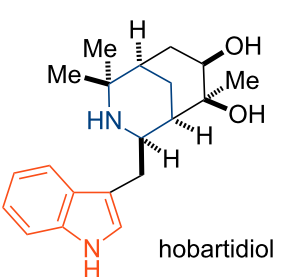

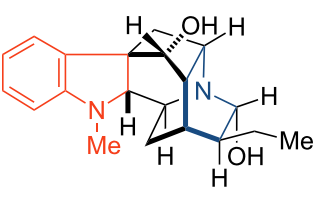

ajmaline

(c) Diversity-oriented synthesis: Build-Couple-Pair strategy

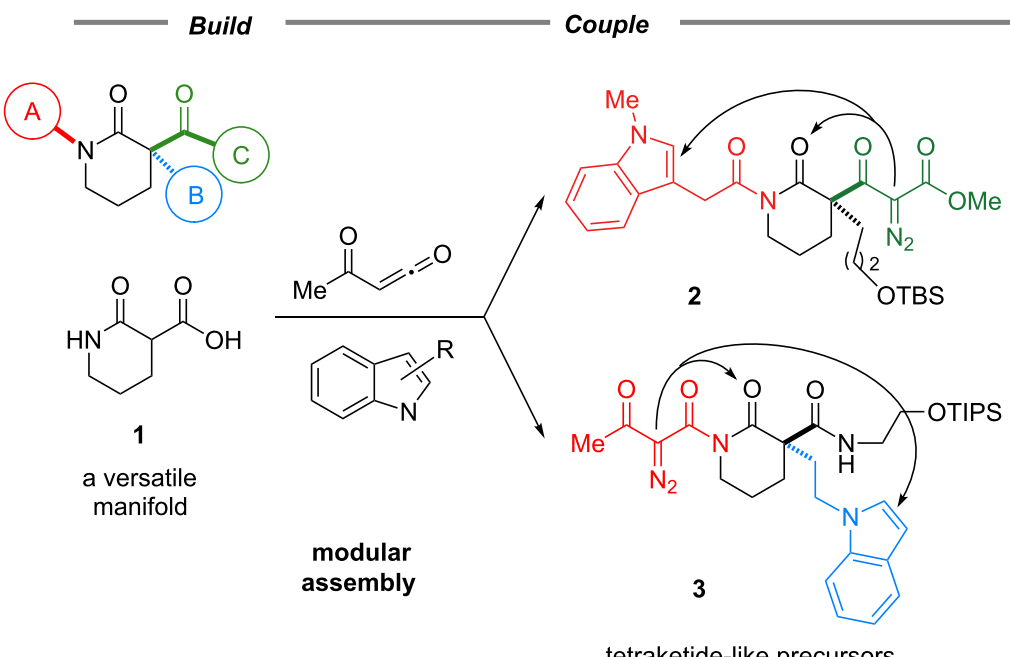

tetraketide-like precursors
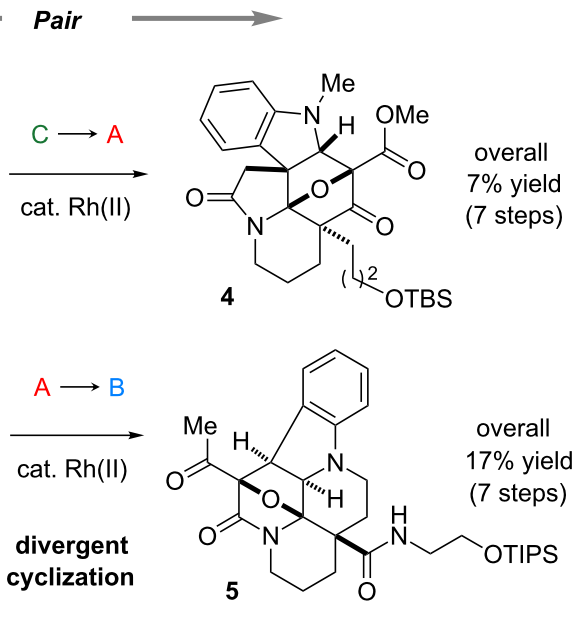

skeletal diversity

Figure 1: (a) Biosynthetic outline of aromatic polyketides; (b) structure of indole alkaloids composed of indole (red) and piperidine (blue) groups; (c) divergent cyclizations to generate scaffold variations as an illustration of the "Build-Couple-Pair" strategy in diversity-oriented synthesis. 
tional groups on 1, $\alpha$-diazoketocarbonyl and indole groups were installed to produce a set of tetraketide-like precursors, $\mathbf{2}$ and $\mathbf{3}$. Rhodium(II)-catalyzed tandem cyclization-cycloaddition [1921] of the tetraketide-like precursors produced distinct multicyclic scaffolds, $\mathbf{4}$ and $\mathbf{5}$, differing in the relative orientations of the substructures. This approach illustrates a systematic way of diversifying skeletal arrays in a controlled manner.
With the intention to produce screening collections, we then devised a second-generation strategy applicable for a parallel synthetic protocol. This approach allows unified four-step access to a series of indole-alkaloid-like scaffolds. Some of these results were previously reported as a preliminary communication in 2009 [22]. As shown in Figure 2a, we conceived the modular assembly of three building blocks onto the piperidine-

(a)<smiles>[R]CNC(=O)C(c1cn([2H])c2ccccc12)N(CC([R])=C([R])[R])C(=O)[C@@]1(C)CCCN(C(=O)C(=O)C(C)=O)C1=O</smiles>
modular assembly

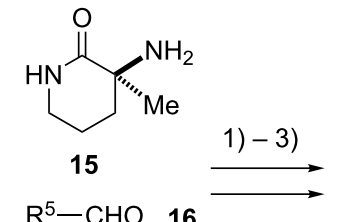

aminoacetal<smiles></smiles><smiles></smiles>
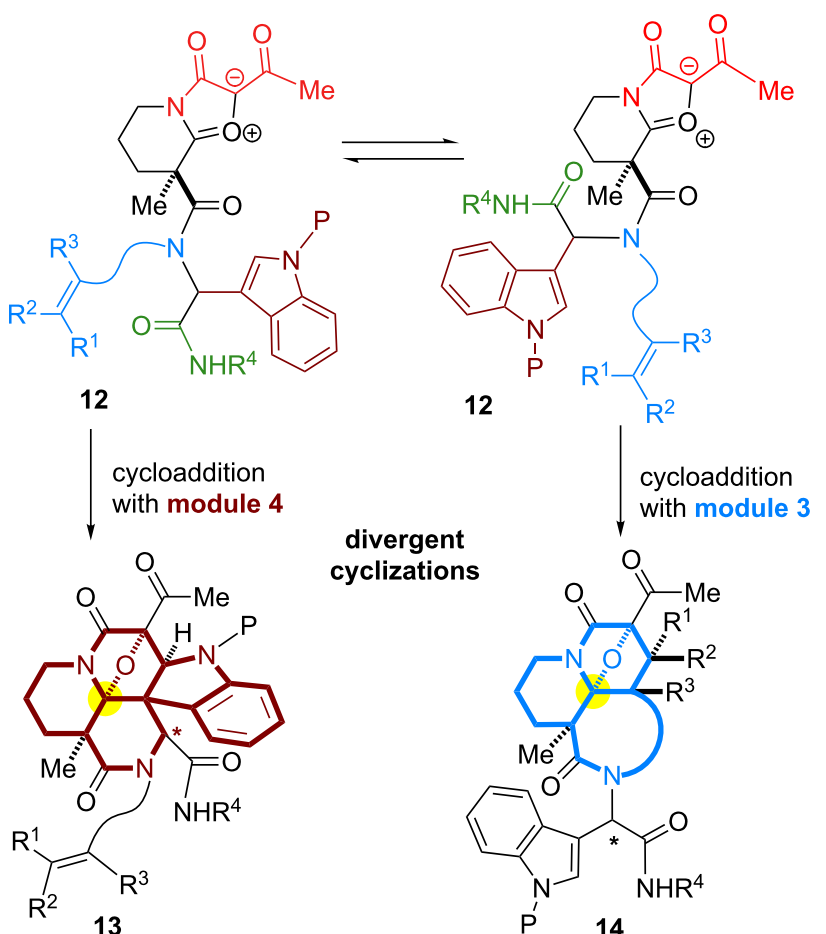

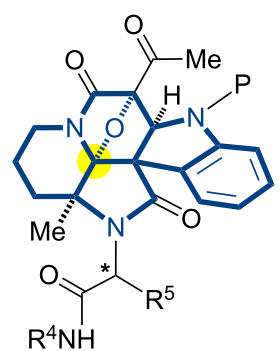

19 divergent cyclizations

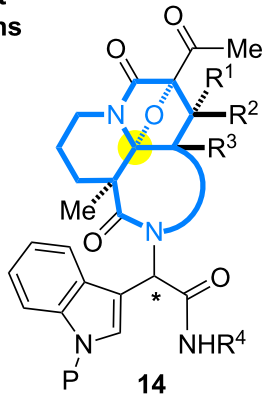

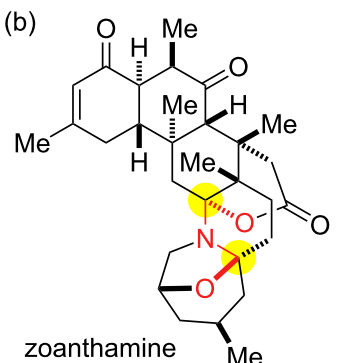

(b)

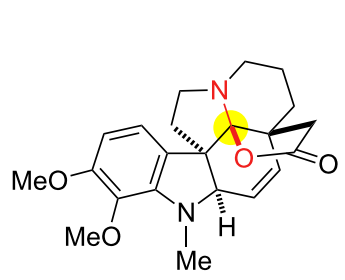

aspidophytine

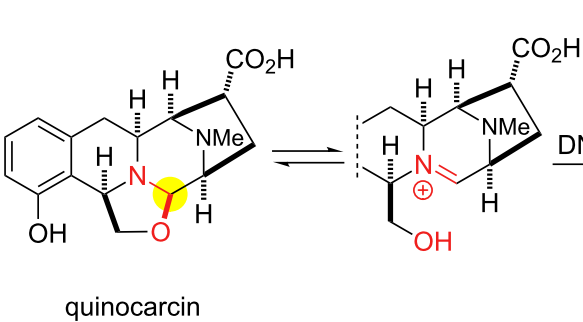

Figure 2: (a) Synthetic plans based on modular assembly and divergent cyclizations leading to fused skeletons; (b) structures of naturally occurring alkaloids bearing aminoacetal moieties and a proposed mode of action of quinocarcin. 
based manifold 6 with a carboxylic acid group. Ugi condensation [23-25] of 6 with indole-3-carbaldehyde 7, isonitrile and amine building blocks 8 and $\mathbf{9}$, followed by reaction with an acetylketene [26] would produce a tetraketide-like precursor $\mathbf{1 0}$ composed of five modules. Since two methylene groups in module 2 in the tetraketide-like moiety $\mathbf{1 0}$ are masked as an imide group and a quaternary center, respectively, the remaining methylene in module 1 would be regiospecifically manipulated through diazotransfer to form diazoimide 11 [27]. Rhodium(II)-catalyzed cyclization of $\mathbf{1 1}$ between modules 1 and 2 could generate a carbonium ylide intermediate $\mathbf{1 2}$. In this system, there is a dynamic conformational equilibrium of the tertiary amide, which is expected to allow divergent cycloadditions with the dipolarophiles installed at modules 3 and 4 leading to either tetracyclic $\mathbf{1 4}$ or hexacyclic 13. In this full account, we also employ a piperidine-based manifold $\mathbf{1 5}$ bearing an amino group in order to expand the applicability of the various building blocks in the four-step parallel synthesis. The modular assembly of $\mathbf{1 5}$ with 16, 17 and $\mathbf{8}$ based on Ugi condensation could produce a different dipeptidyl array of the precursor 18, which is expected to produce the distinct scaffold 19 compared to those produced from manifold 6 . According to this strategy employing rhodium(II)-catalyzed tandem reactions, four $\mathrm{sp}^{2}$-centers were efficiently converted into the corresponding $\mathrm{sp}^{3}$-centers, including an aminoacetal core. In nature, there are a variety of alkaloids that possess an aminoacetal group (Figure 2b). The aminoacetal groups embedded in the skeleton are prone to undergo $\mathrm{C}-\mathrm{O}$ bond cleavage to form electrophilic iminium species, which allow covalent bond formation with biomacromolecules (nucleic acids, proteins) in a cellular environment, and thereby play pivotal roles in defining their biological activities [28,29]. As a mechanistic rationale for the antitumor activities of quinocarcins, DNA alkylation exploiting the iminium moiety was proposed as shown in Figure $2 b[30]$.

Inspired by these biosynthetic strategies, we report herein the development of parallel and four-step synthetic processes, employing manifolds $\mathbf{6}$ and 15, leading to collections of fused molecules with installations of diverse functional groups comprising aminoacetal, $\beta$-ketoimide and indole groups [3134]. Evaluation of in vitro antitrypanosomal activities of the synthetic collections and preliminary SAR studies are also described [35-41].

\section{Results and Discussion}

First, we assembled a linear precursor 24 with installation of a $p$-methoxybenzyl group and an indole ring at modules 3 and 4 , respectively (Scheme 1), according to a procedure previously reported in our preliminary communication [22]. Racemic manifold 6, indole-3-carbaldehyde derivative (20), tert-

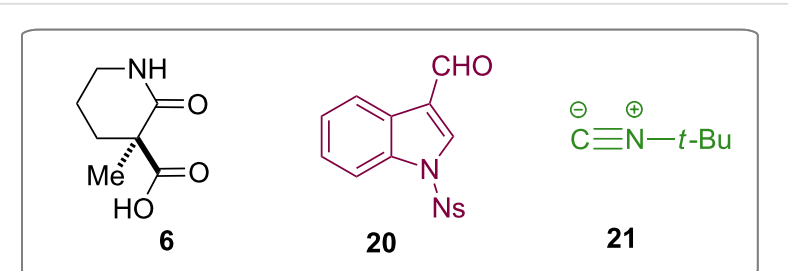

$\mathrm{MeO}$

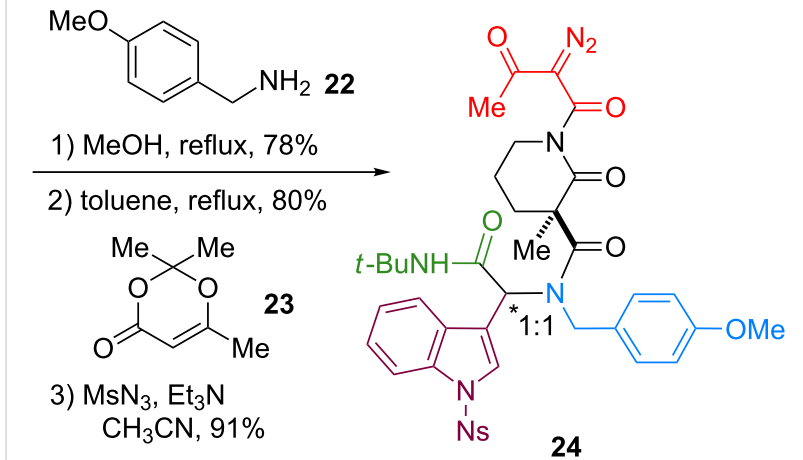

4) $\mathrm{Rh}_{2}(\mathrm{OAc})_{4} \mid$ benzene

$(5 \mathrm{~mol} \%) \downarrow$ reflux, $78 \%$
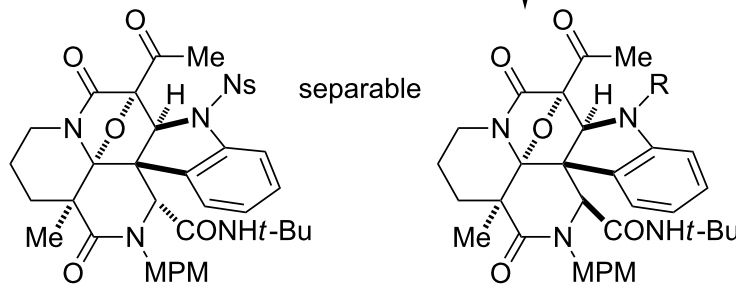

$25 a$

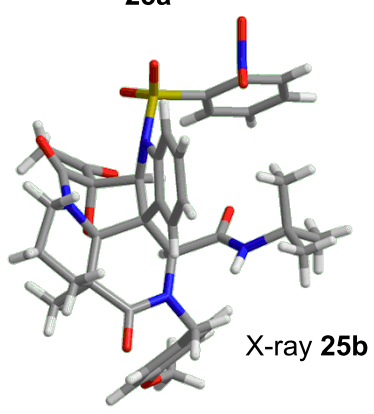

$\mathrm{PhSH}$ 25b: $\mathrm{R}=\mathrm{Ns}$

$\mathrm{Cs}_{2} \mathrm{CO}_{3} \underset{99 \%}{\longrightarrow}$ 26b: $\mathrm{R}=\mathrm{H}$

overall $44 \%$ yield

(4 steps)<smiles>N#[S+]c1ccccc1[N+](=O)[O-]</smiles>

Scheme 1: Four-step synthesis of hexacyclic skeleton 25

butylisonitrile (21) and $p$-methoxybenzylamine (22) were condensed in methanol under reflux to furnish a dipeptidyl product as a 1:1 diastereomeric mixture in $78 \%$ yield. $\mathrm{N}$-Acetoacetylation of this intermediate was achieved by reaction with an acetylketene generated by heating of $\mathbf{2 3}$. Subsequent diazotransfer reaction afforded the precursor $\mathbf{2 4}$ with a diazoimide group in $73 \%$ yield (two steps). Cyclization of 24 and subsequent cycloaddition between the resulting carbonium ylide and the indole $\mathrm{C} 2-\mathrm{C} 3$ double bond efficiently proceeded by the treatment with $5 \mathrm{~mol} \% \mathrm{Rh}_{2}(\mathrm{OAc})_{4}$ catalyst in benzene under reflux to afford hexacyclic scaffold 25 in $78 \%$ yield. The cyclized products were obtained as a 1:1 diastereo- 
meric mixture of 25a and $\mathbf{2 5 b}$ and were easily separable by conventional silica-gel chromatography. X-ray analysis of crystalline 25b unambiguously determined the relative stereochemical relationships of the multiple $\mathrm{sp}^{3}$ centers embedded in the complex hexacyclic scaffold. In addition, removal of the $\mathrm{N}$-nosyl protecting group by treatment with benzenethiol led to 26b in quantitative yield [42].

To generate skeletal variations by altering the sites of the cycloadditions, we next synthesized a branched precursor 29 bearing a pair of identical indole units at modules 3 and 4 (Scheme 2), as reported previously [22]. Due to the instability of the corresponding amine building block bearing the indole unit, azide $\mathbf{2 7}$ was employed as a precursor. Staudinger/azaWittig reaction [43] of $\mathbf{2 7}$ and $\mathbf{2 0}$ and subsequent condensation with $\mathbf{6}$ and $\mathbf{2 1}$ afforded the peptidyl product 28. Installation of a $\beta$-keto imide followed by diazotransfer reaction produced 29. Upon the treatment of $\mathbf{2 9}$ with $\mathrm{Rh}_{2}(\mathrm{OAc})_{4}$ catalyst (5 mol \%), the cycloaddition occurred in a highly site-selective manner at module 3 to form $\mathbf{3 0}$ in $77 \%$ yield. Cycloaddition with the other site (module 4) is likely to be hindered by the sterically demanding amide moiety (module 5 ) in the vicinity of the reaction centers.
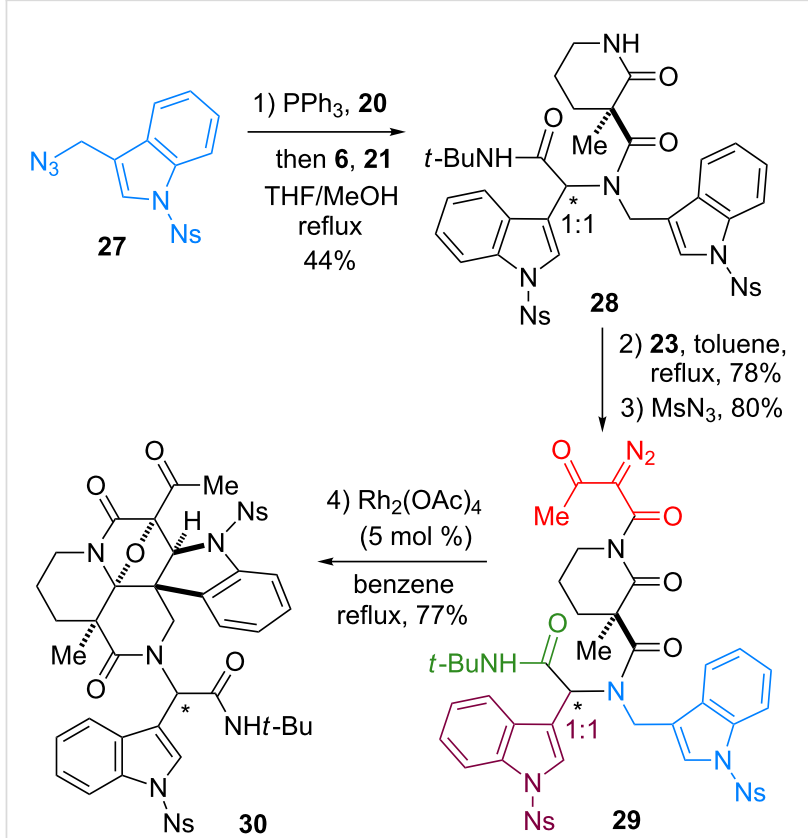

cycloaddition with module 3

Scheme 2: Four-step synthesis of hexacyclic skeleton $\mathbf{3 0}$.

Taking into account the predominant involvement of the dipolarophile installed at module 3 , we then designed a branched precursor 35 having a terminal olefin and an indole group at modules 3 and 4 , respectively (Scheme 3 ). According to the previously reported protocol [22], Ugi reaction employing allylamine (31) and stepwise installation of a diazoimide group provided 35 in good yield. Upon treatment of 35 with $\mathrm{Rh}_{2}(\mathrm{OAc})_{4}$ in benzene under reflux, 1,3-dipolar cycloaddition of the ylide intermediate with the terminal olefin at module 3 proceeded to give 39 as a separable 1:1 diastereomeric mixture in $94 \%$ yield. The relative stereochemistry of $\mathbf{3 9}$ was unambiguously determined by X-ray analysis of the crystalline $\mathbf{3 9 b}$.

In an effort not only to verify the reaction scope of the olefinic group installed at module 3 but also to shift the reaction site (module $3 \rightarrow 4$ ), we then prepared a series of cyclization precursors 36-38 in order of increasing steric hindrance of the olefinic groups as reported previously [22]. Allylamines 32-34 having a di-, tri- or tetra-substituted olefin were employed to synthesize precursors 36-38 based on the unified three-step protocol. The $\mathrm{Rh}(\mathrm{II})$-catalyzed tandem cyclization-cycloaddition of the branched precursors 36-38 exclusively occurred at module 3 . The cyclized products $\mathbf{4 0 - 4 2}$, having the indole group at module 4 intact, were obtained in good yields. It is worth noting that the cycloadditions efficiently incorporated consecutive quaternary centers into the complex fused skeleton, overriding the considerable steric hindrance of the dipolarophiles composed of the tri- and even tetra-substituted olefin groups. To test the generality of the site-selective cycloaddition at module 3 , we then synthesized precursors $\mathbf{4 5}$ and $\mathbf{4 6}$ with a terminal alkyne and a furan ring, respectively, by using amine building blocks 43 and $\mathbf{4 4}$ according to the reported procedure [22]. The $\mathrm{Rh}(\mathrm{II})$-catalyzed tandem reactions of $\mathbf{4 5}$ and $\mathbf{4 6}$ again proceeded at module 3 to produce cyclized products $\mathbf{4 7}$ and $\mathbf{4 8}$ in good yields. Despite our concern for the potential instability of the aminoacetal moiety adjacent to the double bond, $\mathbf{4 7}$ is stable under the standard manipulations. Overall, the pair of diastereomers generated by the Ugi condensations were converted equally through the unified three-step transformations and easily separated after the cycloadditions.

Whilst the cycloadditions described above demonstrate the preference for the dipolarophile installed at module 3 , we then attempted to alter the cyclization mode (module $3 \rightarrow 4$ ) by increasing the entropic barrier for medium-sized ring formation (Scheme 4) as reported previously [22]. For this purpose, we designed precursors $\mathbf{5 1}$ and $\mathbf{5 2}$, synthesized through the threestep protocol employing amines 49 and 50, respectively. Upon the treatment of 51 with $\mathrm{Rh}_{2}(\mathrm{OAc})_{4}$, cycloaddition predominantly occurred at module 3 to produce tetracyclic 53 in $65 \%$ yield with formation of a seven-membered ring. Despite the minor pathway, cycloaddition at module 4 also competed to give 54 in $22 \%$ yield. On the other hand, cycloaddition of $\mathbf{5 2}$ exclusively occurred with the indole group at module 4, giving rise to $\mathbf{5 6}$ in $94 \%$ yield without eight-membered ring formation 


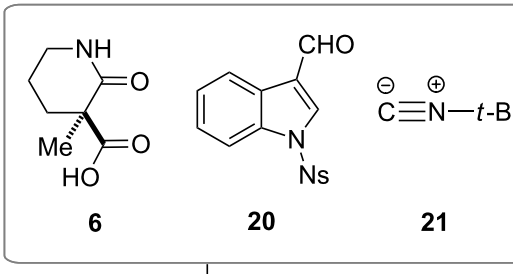

1) $\mathrm{MeOH}$, $\mathrm{H}_{2} \mathrm{~N}$ 31 $\mathrm{MsN}_{3}, \mathrm{Et}_{3} \mathrm{~N}, \mathrm{CH}_{3} \mathrm{CN}, 96 \%$ reflux, $76 \%$<smiles>[Y1][C@@]1(C(=O)N(CC=C)[C@@]([Y])(C(=O)NCCCC)c2cn(S(C)(=O)=O)c3ccccc23)CCCN(C(=O)C(C)=O)C1=O</smiles>

4) $\mathrm{Rh}_{2}(\mathrm{OAc})_{4}$, (5 mol \%) benzene, reflux, $94 \%$
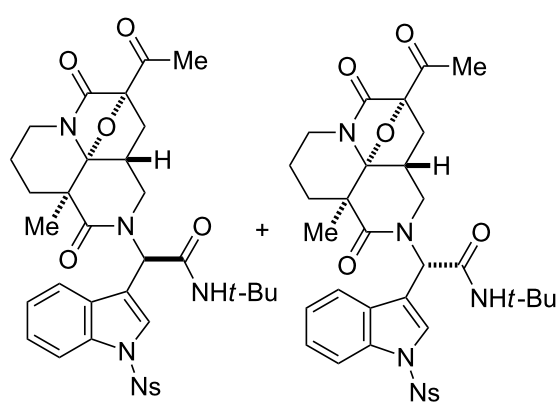

$39 a$ separable

$39 b$

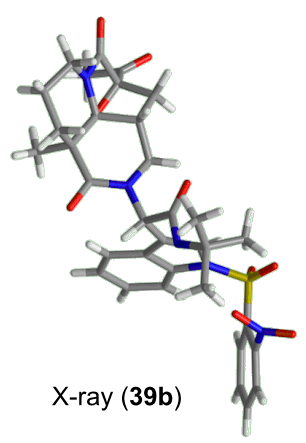

1) $\mathrm{MeOH}$, reflux, $59 \%$

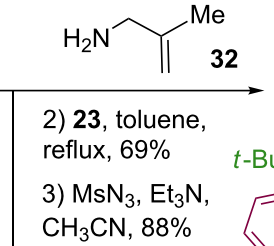

Me

4) $\mathrm{Rh}_{2}(\mathrm{OAc})_{4}$

$\langle\mathrm{N}=\mathrm{N} \quad(5 \mathrm{~mol} \%)$

$=0$ benzene, reflux $83 \%$

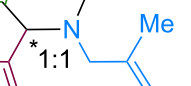<smiles>NC1CN1</smiles>

36

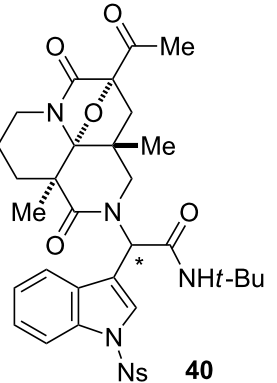

Ns 40

1) $\mathrm{MeOH}$, reflux, $59 \%$
2) 23, toluene,
reflux, 87\%
3) $\mathrm{MsN}_{3}, \mathrm{Et} \mathrm{H}_{3} \mathrm{~N}$,
$\mathrm{CH}_{3} \mathrm{CN}, 84 \%$

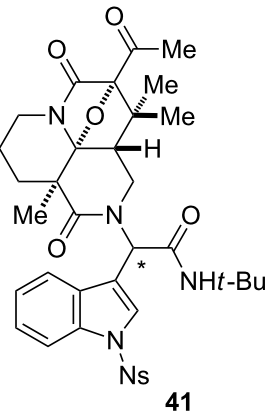

1) $\mathrm{MeOH}$, reflux, $56 \%$

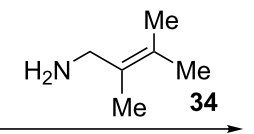

$\sum_{m=0}^{N_{2}}$<smiles>CCCCN1CCCCC1=O</smiles>

4) $\mathrm{Rh}_{2}(\mathrm{OAc})_{4}$

$93 \%$ 2) 23, toluene,
reflux, $93 \%$
3) $\mathrm{MsN}_{3}, \mathrm{Et}_{3} \mathrm{~N}, \mathrm{BuHN}$<smiles></smiles>
$80 \%$

$\mathrm{CH}_{3} \mathrm{CN}, 94 \%$

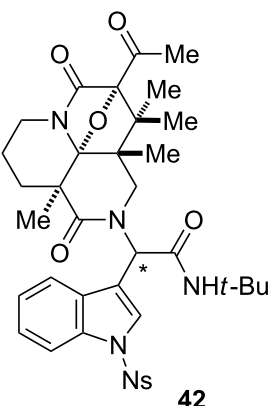

1) $\mathrm{MeOH}$, reflux, $62 \%$<smiles>CNC(=O)C(=N)C(C)=O</smiles>
2) 23 , toluene, Me $\rightleftharpoons$ N $=0$

4) $\mathrm{Rh}_{2}(\mathrm{OAc})_{4}$ 2) 23, toluene, $t$-BuHN $\| \mathrm{Me}=0$ benzene, reflux 3) $\mathrm{MsN}_{3}, \mathrm{Et}_{3} \mathrm{~N}$, $\mathrm{CH}_{3} \mathrm{CN}, 84 \%$

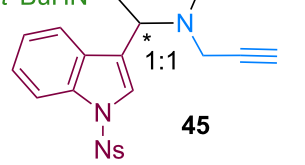

$83 \%$

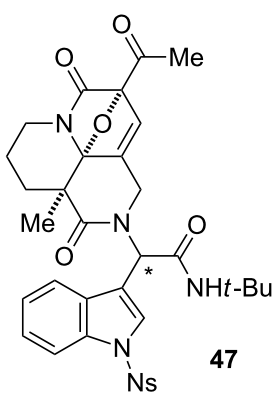

1) $\mathrm{MeOH}$, reflux, $64 \%$

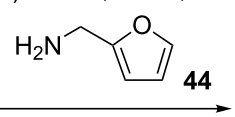

$\sum_{-N}^{O N}=0$

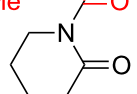

4) $\mathrm{Rh}_{2}(\mathrm{OAc})_{4}$

2) 23, toluene, reflux, $74 \%$ 3) $\mathrm{MsN}_{3}, \mathrm{Et}_{3} \mathrm{~N}$,
$\mathrm{CH}_{3} \mathrm{CN}, 93 \%$

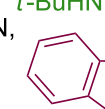

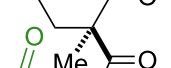

$\langle\mathrm{Me}\rangle=\mathrm{O}$ \rangle$_{*} \mathrm{~N}$ *
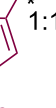

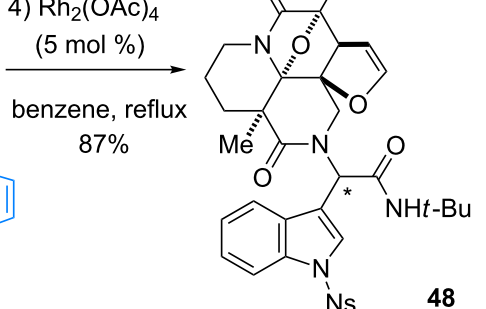

Scheme 3: Parallel and four-step synthesis of tetracyclic skeletons $\mathbf{3 9 - 4 2}$ and $\mathbf{4 7 - 4 8}$ 


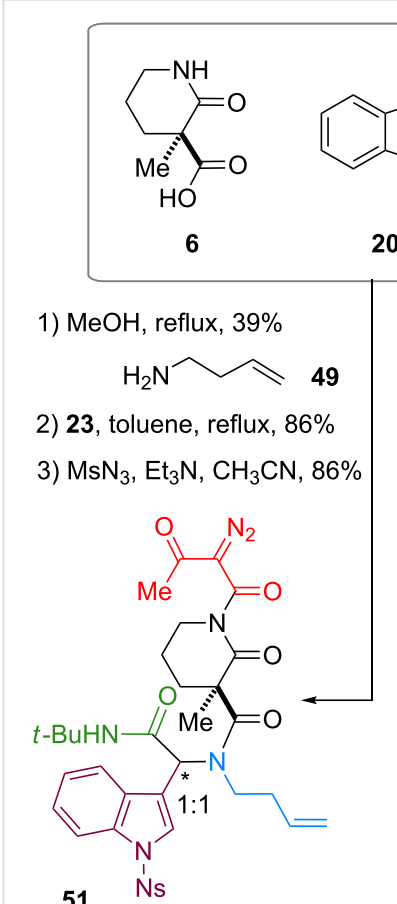

$51 \quad$ No

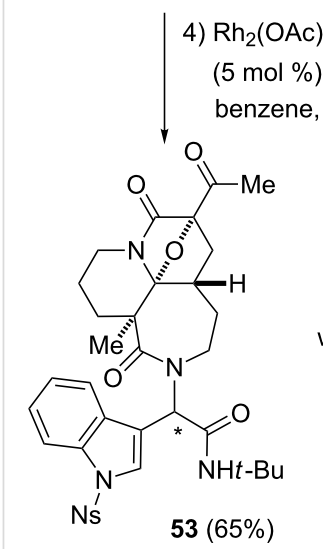

cycloaddition
with module 3<smiles></smiles><smiles>[R4]C(C)(C)C(C)(C)C</smiles>

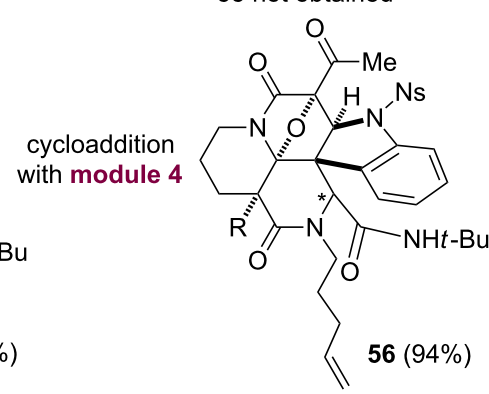

Scheme 4: Synthesis of branched precursors, 51 and $\mathbf{5 2}$, using amines 49 and $\mathbf{5 0}$, with different methylene lengths and attempts to switch reaction sites.

leading to 55. X-ray analysis of the crystalline 56b confirmed the structure [22]. Accordingly, alteration of the cyclization mode was achieved by modulating the ring sizes formed via cycloaddition, which allowed divergent access to hexacyclic and tetracyclic skeletons.
In this study, we designed and synthesized a piperidine-based manifold 15 bearing an amino group in order to produce variations of branched precursors leading to distinct scaffolds (Scheme 5). The manifold $\mathbf{1 5}$ was readily prepared through<smiles>[Y10]C1(NC(=O)OC(C)(C)OCC)CCCNC1=O</smiles>

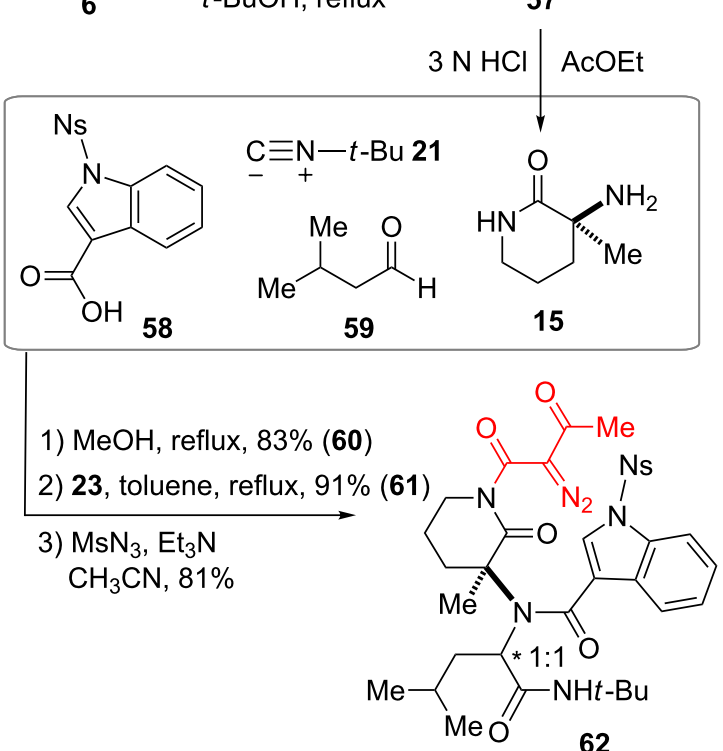

4) $\mathrm{Rh}_{2}(\mathrm{OAc})_{4},(5 \mathrm{~mol} \%)$ benzene, reflux, $95 \%$

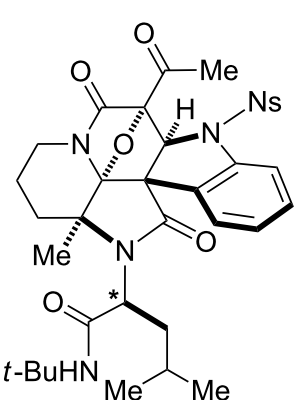

$63 a$

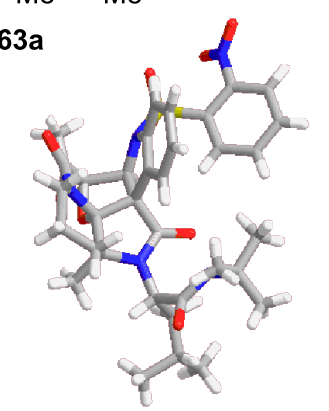

63b

X-ray for $63 a$

Scheme 5: Four-step synthesis of hexacyclic scaffold 63 employing manifold $\mathbf{1 5}$. For details of the synthesis of $\mathbf{6 0}$ and $\mathbf{6 1}$ see Supporting Information File 1. 
Curtius rearrangement of $\mathbf{6}$ and subsequent removal of the resulting carbamate group. Ugi four-component condensation of 15, isonitrile 21, indole-3-carboxylic acid derivative $\mathbf{5 8}$ and aldehyde 59 produced a 1:1 diastereomeric mixture of the dipeptidyl intermediate. Stepwise installation of the $\alpha$-diazocarbonyl group produced $\mathbf{6 2}$ in good yield. The cyclization precursor $\mathbf{6 2}$ has a different arrangement of the branched dipeptidyl unit linked to the piperidine-based manifold compared with those derived from 6 . Rhodium-catalyzed tandem cyclization-cycloaddition proceeded smoothly to produce $\mathbf{6 3}$ in $95 \%$ yield. After separation of the diastereomers, X-ray analysis of crystalline 63a allowed its structural determination. The flexibility and divergence of the synthetic process with high levels of stereoselectivity are promising for the development of smallmolecule libraries with structural diversity and complexity.

With collections of the natural-product-inspired molecules in hand, in vitro anti-trypanosomal activities [35-41] were evaluated by employing a GUTat 3.1 strain of T. brucei brucei (Table 1) according to the previously reported protocols (Supporting Information File 1). We found several hit compounds in the series of the cycloadducts exploiting module 3 as

Table 1: In vitro anti-trypanosomal activities of natural product analogues and approved drugs against T. brucei brucei GUTat $3.1^{\mathrm{a}}$.

entry

compound
$\mathrm{IC}_{50}(\mu \mathrm{g} / \mathrm{mL})$

anti-trypanosoma activity
Selectivity Index (SI)

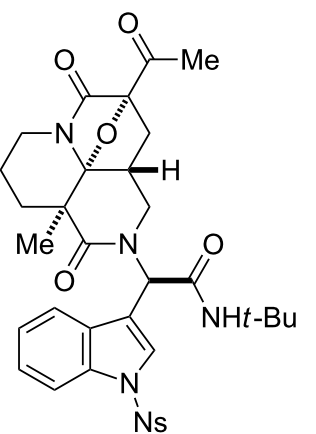

$39 a$

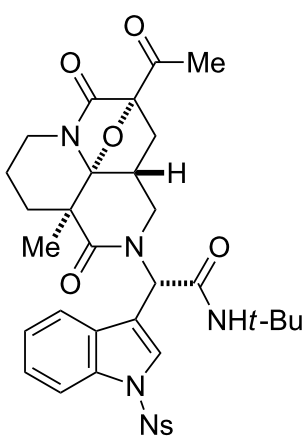

$39 b$

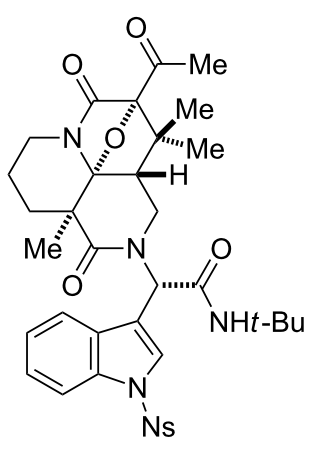

41b 
Table 1: In vitro anti-trypanosomal activities of natural product analogues and approved drugs against T. brucei brucei GUTat 3.1 ${ }^{\mathrm{a}}$. (continued)

4

5

6

7

8

9

10

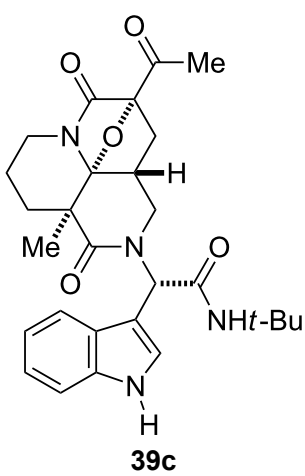

$>12.5$

$N D^{b}$

(-)

5.9

24.47

4.1<smiles>CCC(C)NC(=O)CN(Cc1ccc(OC)cc1)C(=O)C[14CH3]</smiles>

$25 a$
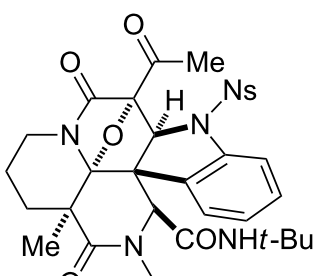<smiles>COCCc1ccc(OC)cc1</smiles>

25b

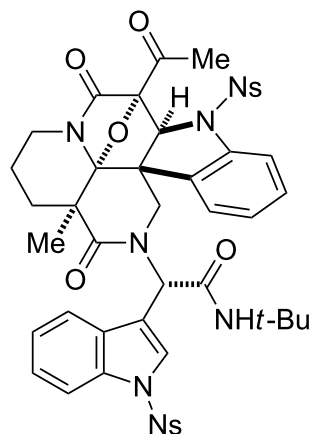

pentamidine $^{c}$

suramin $^{\mathrm{C}}$

eflornithine ${ }^{c}$
$>12.5$

$N D^{b}$

(-)

$>12.5$

$N D^{b}$

(-)

$\begin{array}{ccc}0.00158 & 5.71 & 3600 \\ 1.58 & >100 & >63 \\ 2.27 & >100 & >44\end{array}$

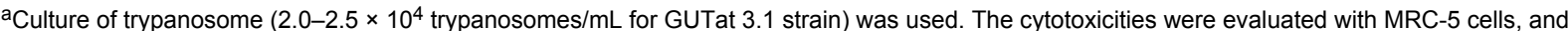
the selectivity index $(\mathrm{SI})$ for trypanosomiasis was calculated as $\left(\mathrm{IC}_{50}\right.$ for MRC-5)/(IC 50 for $T$. brucei brucei). ' $\mathrm{ND}$ means "not determined". "Existing antitrypanosomal drugs. 
dipolarophiles. While compound 39a shows negligible activities, the diastereomer $39 \mathbf{b}$ exhibits the most potent activity $\left(\mathrm{IC}_{50}=0.46 \mu \mathrm{g} / \mathrm{mL}\right)$, indicating the critical importance of the stereochemistry on the peptidyl unit (Table 1, entries 1 and 2). The $\mathrm{IC}_{50}$ value of the antitrypanosomal activity is comparable to or greater than those of the approved drugs, suramine and eflornithine. Unfortunately, 39b exhibits relatively potent cytotoxicity $\left(\mathrm{IC}_{50}=4.02 \mu \mathrm{g} / \mathrm{mL}\right.$ ) against a human cell line (MRC-5 cells), and its selectivity index (SI) is calculated to be 8.7 as a means to assess the combined potencies of both antitrypanosomal and cytotoxic activities. Incorporation of dimethyl substituents on the scaffold resulted in diminished activity (41b: $\left.\mathrm{IC}_{50}=5.89 \mu \mathrm{g} / \mathrm{mL}\right)$ (Table 1 , entry 3$)$. Removal of the nosyl group $(\mathbf{3 9 b} \rightarrow \mathbf{3 9 c})$ also caused substantial loss of the activities, suggesting the critical role of the aromatic sulfone amide moiety (Table 1, entry 4). Aside from 25a, which shows moderate activity $\left(\mathrm{IC}_{50}=5.9 \mu \mathrm{g} / \mathrm{mL}\right)$ (Table 1 , entry 5$)$, the antitrypanosomal activities of hexacyclic compounds, $\mathbf{2 5} \mathbf{b}$ and 30b, (Table 1, entries 6 and 7) are negligible. In addition, the hexacycles (63a and 63b) generated from manifold $\mathbf{1 5}$ also showed insignificant activities (data not shown). Thus, this preliminary assessment supports the idea that the collections of natural-product-inspired scaffolds could have high hit rates against biological screenings, even without having structural information about the biological targets and small-molecule modulators related to the targeted cellular functions. Further screening investigations of the synthetic collections prepared in the four-step process are currently underway in our laboratories.

\section{Conclusion}

Inspired by biosynthetic strategies, we devised a modular assembly of five components employing manifold $\mathbf{6}$ and subsequent installation of a diazoimide group. This allowed threestep access to collections of cyclization precursors with a linkage of the piperidine and the indole units as key substructures shared with naturally occurring alkaloids. Rhodiumcatalyzed cyclizations of diazoimides and subsequent divergent cycloadditions produced tetracyclic and hexacyclic scaffolds with exquisite regio- and stereocontrols. By the choice of dipolarophiles incorporated in modules 3 and 4, we have demonstrated site-selective cycloadditions leading to distinct scaffolds, which could be a rational approach to generate skeletal variations in synthetic collections. We further demonstrated the applicability of the manifold $\mathbf{1 5}$ bearing an amino group, which elicits further scaffold diversity. The parallel synthetic process based on the unified four-step sequences allows installation of dense arrays of various functional groups featuring aminoacetal, $\beta$-ketoimide and indole/olefin groups into multicyclic scaffolds reminiscent of natural products. Evaluation of antitrypanosomal activities of the collections allowed primary screenings of several hit compounds. The preliminary SAR study provided insights into the potential pharmacophore, based on the key features of scaffold, substructure and stereochemistry, which could be the proof of concept of our synthetic approach toward lead generation exploiting natural-productinspired collections.

\section{Supporting Information}

\section{Supporting Information File 1}

Experimental procedures and NMR spectra of compounds.

[http://www.beilstein-journals.org/bjoc/content/

supplementary/1860-5397-8-105-S1.pdf]

\section{Acknowledgements}

We thank Prof. Kiyoshi Tsuge (University of Toyama) and Yuko Fujimura (Shionogi \& Co., Ltd.) for performing the X-ray analysis of crystalline compounds. This work was supported by Grants-in-Aid for Challenging Exploratory Research [20651054] and Scientific Research (B) [23310156] to H. Oguri and also supported in part by FINDS: pharma-innovation discovery competition Shionogi, the Naito Foundation, the Drugs for Neglected Diseases initiative (DND $i$ ), and the Science and Technology Research Partnership for Sustainable Development (SATREPS) program of the Japan Science and Technology Agency (JST). A fellowship to H. M. from the JSPS is gratefully acknowledged. We also thank Ms. Miyuki Namatame (Kitasato University) for her technical assistance.

\section{References}

1. Ganesan, A. Curr. Opin. Chem. Biol. 2008, 12, 306-317. doi:10.1016/j.cbpa.2008.03.016

2. Li, J. W.-H.; Vederas, J. C. Science 2009, 325, 161-165. doi:10.1126/science.1168243

3. Clemons, P. A.; Bodycombe, N. E.; Carrinski, H. A.; Wilson, J. A.; Shamji, A. F.; Wagner, B. K.; Koehler, A. N.; Schreiber, S. L. Proc. Natl. Acad. Sci. U. S. A. 2010, 107, 18787-18792. doi:10.1073/pnas.1012741107

4. Walsh, C. T.; Fischbach, M. A. J. Am. Chem. Soc. 2010, 132, 2469-2493. doi:10.1021/ja909118a

5. Dewick, P. M. The Acetate Pathway: Fatty acids and Polyketides. Medicinal Natural Products: A Biosynthetic Approach, 3rd ed.; John Wiely \& Sons, Ltd.: Chichester, U.K., 2009; pp 39-135.

6. Saxton, J. E. Alkaloids of the Aspidospermine Group. In The Alkaloids: Chemistry and Biology; Cordell, G. A., Ed.; Academic Press: San Diego, CA, 1998; Vol. 51, pp 1-197.

7. Nielsen, T. E.; Schreiber, S. L. Angew. Chem., Int. Ed. 2008, 47, 48-56. doi:10.1002/anie.200703073

8. Schreiber, S. L. Nature 2009, 457, 153-154. doi:10.1038/457153a

9. Mitchell, J. M.; Shaw, J. T. Angew. Chem., Int. Ed. 2006, 45, 1722-1726. doi:10.1002/anie.200503341

10. Kumagai, N.; Muncipinto, G.; Schreiber, S. L. Angew. Chem., Int. Ed. 2006, 45, 3635-3638. doi:10.1002/anie.200600497 
11. Comer, E.; Rohan, E.; Deng, L.; Porco, J. A., Jr. Org. Lett. 2007, 9, 2123-2126. doi:10.1021/ol070606t

12. Sunderhaus, J. D.; Martin, S. F. Chem.-Eur. J. 2009, 15, 1300-1308. doi:10.1002/chem.200802140

13. O'Leary-Steele, C.; Pedersen, P. J.; James, T.; Lanyon-Hogg, T.; Leach, S.; Hayes, J.; Nelson, A. Chem.-Eur. J. 2010, 16, 9563-9571. doi:10.1002/chem.201000707

14. Bauer, R. A.; DiBlasi, C. M.; Tan, D. S. Org. Lett. 2010, 12, 2084-2087. doi:10.1021/ol100574y

15. Marcaurelle, L. A.; Comer, E.; Dandapani, S.; Duvall, J. R.; Gerard, B.; Kesavan, S.; Lee, M. D., IV; Liu, H.; Lowe, J. T.; Marie, J.-C.; Mulrooney, C. A.; Pandya, B. A.; Rowley, A.; Ryba, T. D.; Suh, B.-C.; Wei, J.; Young, D. W.; Akella, L. B.; Ross, N. T.; Zhang, Y.-L.; Fass, D. M.; Reis, S. A.; Zhao, W.-N.; Haggarty, S. J.; Palmer, M.; Foley, M. A. J. Am. Chem. Soc. 2010, 132, 16962-16976. doi:10.1021/ja105119r

16. Schreiber, S. L. Science 2000, 287, 1964-1969. doi:10.1126/science.287.5460.1964

17. Galloway, W. R. J. D.; Isidro-Llobet, A.; Spring, D. R. Nat. Commun. 2010, 1, No. 80. doi:10.1038/ncomms1081

18. Oguri, H.; Schreiber, S. L. Org. Lett. 2005, 7, 47-50. doi:10.1021/ol047945w

19. Padwa, A.; Hornbuckle, S. F. Chem. Rev. 1991, 91, 263-309. doi:10.1021/cr00003a001

20. Padwa, A.; Weingarten, M. D. Chem. Rev. 1996, 96, 223-270. doi:10.1021/cr950022h

21. Padwa, A. Pure Appl. Chem. 2004, 76, 1933-1952. doi:10.1351/pac200476111933

22. Mizoguchi, H.; Oguri, H.; Tsuge, K.; Oikawa, H. Org. Lett. 2009, 11, 3016-3019. doi:10.1021/ol901020a

23. Dömling, A.; Ugi, I. Angew. Chem., Int. Ed. 2000, 39, 3168-3210. doi:10.1002/1521-3773(20000915)39:18<3168::AID-ANIE3168>3.0.CO ;2-U

24. Zhu, J. Eur. J. Org. Chem. 2003, 1133-1144. doi:10.1002/ejoc.200390167

25. Dömling, A. Chem. Rev. 2006, 106, 17-89. doi:10.1021/cr0505728

26. Reber, K. P.; Tilley, S. D.; Sorensen, E. J. Chem. Soc. Rev. 2009, 38, 3022-3034. doi:10.1039/b912599j

27. Zhang, Z.; Wang, J. Tetrahedron 2008, 64, 6577-6605. doi:10.1016/j.tet.2008.04.074

28. Hirai, G.; Oguri, H.; Hayashi, M.; Koyama, K.; Koizumi, Y.; Moharram, S. M.; Hirama, M. Bioorg. Med. Chem. Lett. 2004, 14, 2647-2651. doi:10.1016/j.bmcl.2004.02.064

29. Scott, J. D.; Williams, R. M. Chem. Rev. 2002, 102, 1669-1730. doi:10.1021/cr010212u

30. Hill, G. C.; Wunz, T. P.; Remers, W. A. J. Comput.-Aided Mol. Des. 1988, 2, 91-106. doi:10.1007/BF01532085

31. Boldi, A. M. Curr. Opin. Chem. Biol. 2004, 8, 281-286. doi:10.1016/j.cbpa.2004.04.010

32. Kumar, K.; Waldmann, H. Angew. Chem., Int. Ed. 2009, 48, 3224-3242. doi:10.1002/anie.200803437

33. Bauer, R. A.; Wurst, J. M.; Tan, D. S. Curr. Opin. Chem. Biol. 2010, 14, 308-314. doi:10.1016/j.cbpa.2010.02.001

34. Ishigaki, Y.; Mahendar, V.; Oguri, H.; Oikawa, H. Chem. Commun. 2010, 46, 3304-3305. doi:10.1039/b926676c

35. Oguri, H.; Hiruma, T.; Yamagishi, Y.; Oikawa, H.; Ishiyama, A.; Otoguro, K.; Yamada, H.; Ōmura, S. J. Am. Chem. Soc. 2011, 133 , 7096-7105. doi:10.1021/ja200374q
36. Otoguro, K.; Ishiyama, A.; Namatame, M.; Nishihara, A.; Furusawa, T.; Masuma, R.; Shiomi, K.; Takahashi, Y.; Yamada, H.; Ōmura, S. J. Antibiot. 2008, 61, 372-378. doi:10.1038/ja.2008.52

37. Toriizuka, Y.; Kinoshita, E.; Kogure, N.; Kitajima, M.; Ishiyama, A.; Otoguro, K.; Yamada, H.; Ōmura, S.; Takayama, H. Bioorg. Med. Chem. 2008, 16, 10182-10189. doi:10.1016/j.bmc.2008.10.061

38. Ishiyama, A.; Otoguro, K.; Iwatsuki, M.; Namatame, M.; Nishihara, A.; Nonaka, K.; Kinoshita, Y.; Takahashi, Y.; Masuma, R.; Shiomi, K.; Yamada, H.; Ōmura, S. J. Antibiot. 2009, 62, 303-308. doi:10.1038/ja.2009.32

39. Iwatsuki, M.; Kinoshita, Y.; Niitsuma, M.; Hashida, J.; Mori, M.; Ishiyama, A.; Namatame, M.; Nishihara-Tsukashima, A.; Nonaka, K.; Masuma, R.; Otoguro, K.; Yamada, H.; Shiomi, K.; Ōmura, S. J. Antibiot. 2010, 63, 331-333. doi:10.1038/ja.2010.41

40. Otoguro, K.; Iwatsuki, M.; Ishiyama, A.; Namatame, M.; Nishihara-Tsukashima, A.; Kiyohara, H.; Hashimoto, T.; Asakawa, Y.; Ōmura, S.; Yamada, H. Phytochemistry 2011, 72, 2024-2030. doi:10.1016/j.phytochem.2011.07.015

41. Ishiyama, A.; Otoguro, K.; Iwatsuki, M.; Namatame, M.; Nishihara-Tsukashima, A.; Takahashi, Y.; Onodera, H.; Yamada, H.; Ōmura, S. J. Antibiot. 2012, 65, 113-114. doi:10.1038/ja.2011.118

42. Fukuyama, T.; Jow, C.-K.; Cheung, M. Tetrahedron Lett. 1995, 36, 6373-6374. doi:10.1016/0040-4039(95)01316-A

43. Timmer, M. S. M.; Risseeuw, M. D. P.; Verdoes, M.; Filippov, D. V.; Plaisier, J. R.; van der Marel, G. A.; Overkleeft, H. S.; van Boom, J. H. Tetrahedron: Asymmetry 2005, 16, 177-185. doi:10.1016/j.tetasy.2004.11.079

\section{License and Terms}

This is an Open Access article under the terms of the Creative Commons Attribution License (http://creativecommons.org/licenses/by/2.0), which permits unrestricted use, distribution, and reproduction in any medium, provided the original work is properly cited.

The license is subject to the Beilstein Journal of Organic Chemistry terms and conditions:

(http://www.beilstein-journals.org/bjoc)

The definitive version of this article is the electronic one which can be found at: doi:10.3762/bjoc. 8.105 